\title{
UI/UX Mobile Games Transformation towards Translated Language
}

\author{
Case Study : Ragnarok Mobile Eternal Love
}

\author{
Andreas Kurniawan \\ New Media Program \\ Visual Communication Design Department \\ Bina Nusantara University \\ Jakarta, Indonesia 11480 \\ andreas.kurniawan@binus.ac.id
}

\author{
Hervina Dyah Aprilia \\ New Media Program \\ Visual Communication Design Department \\ Bina Nusantara University \\ Jakarta, Indonesia 11480 \\ hervina.aprilia@binus.ac.id
}

\begin{abstract}
The purpose of this research study is to get data of user experience towards mobile game design and the transformation of its interface due to translated language. Most of popular mobile games came from China with their local language and writing system. Chinese alphabetic is appropriate for vertical or horizontal orientation, but English and Indonesian alphabetic are not appropriate with vertical orientation. Ragnarok M: Eternal Love with MMORPG's genre is the game sample model, originally from China server and now this game is translated into several languages such as English and Bahasa Indonesia. Ragnarok M: Eternal Love's game developer used a unique method with combined icon and text in order to solve layout's problem that they encounter when converted in to several languages. We conduct the experiment within 2 period of time, based on 25 participants (gamer), all participants tried user interface from a game model sample. The result confirmed that the display of the UI (user interface) used by the developer team of Ragnarok M: Eternal Love, had demonstrated a good solution in developing a user interface for mobile game, when confronted by fixed layout and forced to adapt to various different language, but it still need some adjustment time to fully understand the function of every button.
\end{abstract}

Keywords: user interface, user experience, language, Ragnarok, game mobile

\section{INTRODUCTION}

The increasing demand for mobile games in this era, have opened a new playing field for user interface and user experience design. The transformation of digital media and mobile phone changes user experience to be more complex and multidimensional, user experience web design with desktop computer is not similar to mobile phone. Before smart phones generation became available to users, mobile games were less attractive. Mobile phone's small screen with complicated of control buttons were the main problem for several mobile game creators. Therefore, only a few people played mobile games. Nevertheless, the advent of smart phones, game developer made a huge number of games and even more game genres available for mobile phone users[1]. Famous developer engine created mobile games and unique applications to their customers via google store or app store. Game interface, gameplay, and experience of mobile game should be efficient. Complicated screens are going to be a big problem for users.
Every images, icons and textual information should be as simple as possible. The game simplicity must be considered since small screen in mobile phone and this may cause difficulties towards user interface and user experience itself. Playability about game's environment is the important factors in making a successful mobile game, and the existing playability problems have to be identified and solved before that game is ready to be released.

Best design user interface (UI) layout is the important things for every gamers, not only for fun but now several mobile games were turning into the prestige game which has a big tournament (eSports) with a big amount of prize, in study from J.Smith told eSports (electronic sports). It is where players compete playing computer games (i.e., mobile games) The eSports boom began in the second half of the 2000's as games like Starcraft and Counter-Strike became mainstream, internet media helped eSports become mainstream was the addition of many streaming services such as Youtube and TwitchTV. People whose dedicated to be a professional gamers seriously need a best user interface and experience game design for support them in winning the battle or tournament [2].

Over the last decade, game genre Massively Multiplayer Online Role-Playing Game (MMORPGs) have become big business with huge income. In order to win this game, every player pay a monthly subscription to the game developer who hosts the game and provide content updates. Not only premium subscription, player also need to buy "item mall" in order to improve their character in real game environment, thus, that player can earn win when against the monster or other players. In the other hand, game developer for MMORPG must understand their market, and know how to manage long-term player journey[3].

For every gamer, a good UI (user interface) layout is crucial. Customer will be confused if they do not understand how to operate the interface button. Most of the best seller mobile phones via google store or app store at Indonesia came from China, for example is Ragnarok M: Eternal Love (Gravity Co., Ltd, Dream Square, X.D. NETWORK INC), an open world mobile MMORPG (Massively Multiplayer Online RolePlaying Game) based on the ever famous computer games 
Ragnarok Online from 2003 (distributed by Lytogame in Indonesia). Ragnarok $\mathrm{M}$ : Eternal Love first released to China market at 2017, with Chinese language [4].Today, Ragnarok M: Eternal Love come to South East Asia with different language, such as Thailand, Vietnam, Indonesia and English. It means, main language in the real game environment was turning to several languages. Originated from South Korea Ragnarok Online is a game online in books and games which is popular in the world especially South East Asia. In this case, Ragnarok is used as a background setting of a comic book, which created by Lee Myung Jin and Ragnarok MMORPG based on that comic book. Ragnarok Online is a virtual representation of reality, it creates and represents visual social semiotics, which became very important element of communication in recent years[5]In order to understand gameplay of Ragnarok M: Eternal Love, user needs to learn the basic knowledge to play this game. Every player can customize their characters, in terms of hair style and color, or customize their avatar. By the beginning of this game, players need to control their own character from zero to hero. Novice is the first tittle's character in this game, after doing several activities and quests, players can choose their job such as archer, sword man, magician, thief, merchant and acolyte. Every job also has a unique skill, for instance; archer can use an arrow, acolyte can heal their friends and sword man able to use a shield to defend their team from monster's attack. Players must take their journey through cities, forest, mountain, cavern, beach, island, etc. Ragnarok player will get experience points (EXP) from killing monsters or take any quests from NPC (NonPlayable Character), Ragnarok M: Eternal Love's use a currency called Zeny. Players can earn Zeny by doing some quests or get it from monster they have killed, this Zeny will be used for buy any items or equipment for improve their characters[6].Every player also can communicate with other players by chat window system, and also they can make a Guilds (group of player who play and socialize together).

According interview with Ragnarok M: Eternal Love game producer. Wanli Xin, he told about transformation UI design because that layout design must be changed towards any different languages [7].The main problem conversion from Ragnarok M: Eternal Love with Chinese version to SEA (South East Asia) version design layout of mobile phone interface is about size and shape of button in real game environment.

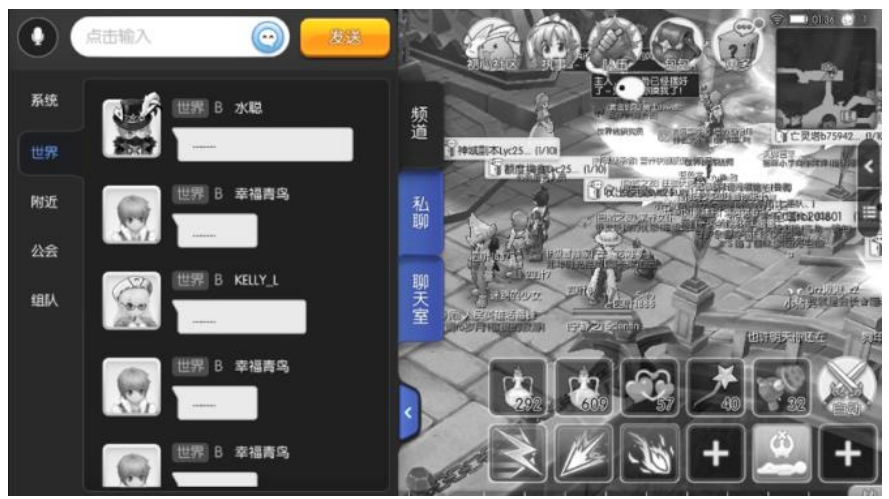

Fig. 1. Ragnarok M : Eternal Love chat interface - Chinese version
According to the window chat interface taken from Ragnarok M: Eternal Love from Chinese version, the button has a vertical Chinese typeface (Channel Chat, Whisper Chat and Private Room Chat), This design has a fixed size button, also appropriate and match with the layout itself. Vertical text is the traditional mode of text layout for many East Asian country, such as Chinese or Japanese. There were so many literatures found with vertical text in the history of China. Vertical text is not same with graphical rotation [8].

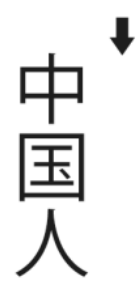

vertical text

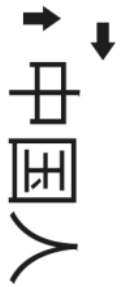

graphical rotation
Fig. 2. Chinese language with vertical and graphical rotation text flow

Ragnarok M: Eternal Love released for South East Asia region country, and this layout will meet several reactions. Normally, Indonesian citizen always read horizontal text (from left to right). Nevertheless, in order to keep size and proportion of the fixed layout from Ragnarok M: Eternal Love, it means English or Indonesia alphabetical also needs to be vertical. Previous study about vertical language by Deyue Yu said that there are 3 formats to convert English text in vertical way; the first is by making the upright letters arranged vertically (marquee), the second format is by rotating horizontal text $90 \mathrm{o}$ clockwise and the third format is by rotating horizontal text counterclockwise[9]. Another research study from Byrne explained that English alphabetical language with horizontal text is fastest and easy to user, followed by both rotated conditions, and the worst is marquee-style presentation[10].

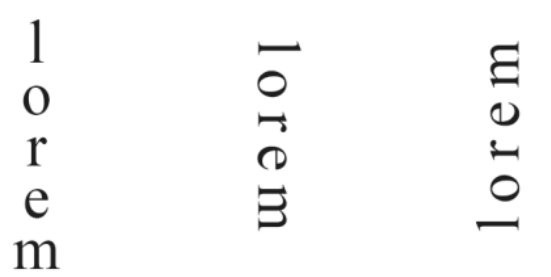

Fig. 3. From left to right: marquee-style, right rotated, left rotated

The previous study explained how English language in alphabetical order would have a better readability when translated in horizontal way, not in the vertical way. Ragnarok M: Eternal Love design layout with fixed size button that gives text in horizontal way is inapplicable. In this case, English and Indonesian language use the same alphabetical type. Another thing to put in consideration is how game mobile design interface must be accepted by user in the best suggestion text layout. In order to keep the fixed layout system penetrated to 
South East Asia server, game developer of Ragnarok M: Eternal Love changed that text button into an icon.

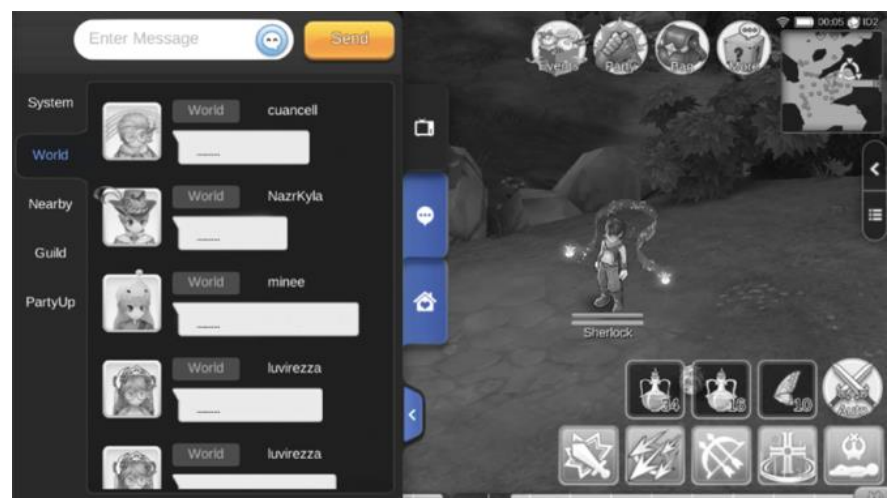

Fig. 4. Ragnarok M : Eternal Love chat interface - SEA version

The word "icon" originates from Greek language, with "eikon" and the original meaning is the image. Based on the history, this icon used for religious totem. Today, this concept used for multiple language purposes. This concept is now commonplace in airports, public services, railway and on roads. Today, every smartphone screens provide so many of icons, after the user downloaded application from google store or app store, user will meet a lot of application with icon based menus that are arranged with fixed grid layout. This menu also help user to organize, find and use their apps[10]. The used of icons in human interaction are very common these days. Generally, an icon consists of 2 elements: a figural image or a textual label. An icon must be understood by user or viewer, if users cannot understand the icons implementation, then the icons completely useless. In general, an icon can embody a basic form of figures, animals, plants, object [11]. Although this concept can help for multiple language, but in many cases, user meet multi interpretation in order to read the icons. Over the past decades, study of icon usage interaction published in various fields such as psychology, design, computer science and technology. The important result from this study is about that users understanding with only icons were slower than those using text or combined icons with text[12]. Ragnarok M: Eternal love was an example for layout design with multiple language purposes. Game developer team choose icon instead of text in their button interface, but in order to support user experience, they also give mechanism that text information box will appear for 1 second when that icon button was pressed by user, but after 1 second, this text box information will disappear from screen.

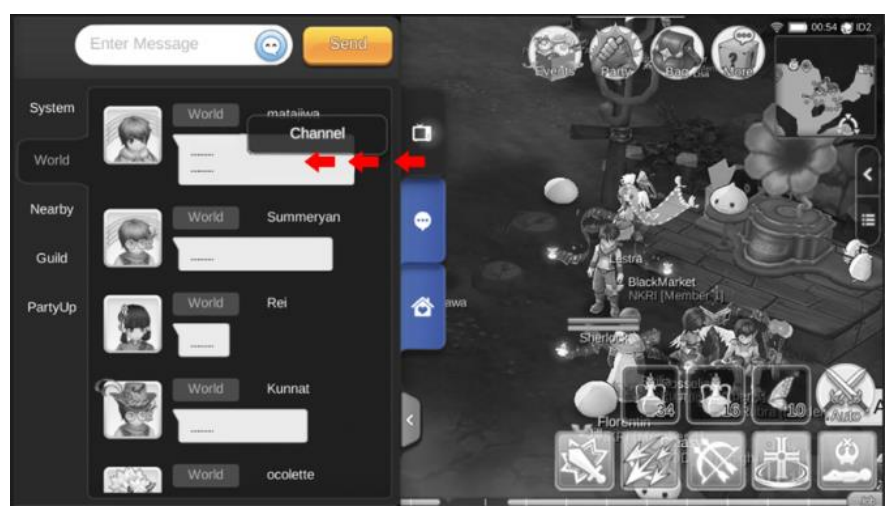

Fig. 5. Ragnarok M : Eternal Love chat interface with text - SEA version

According to Fig 5. If user pressed the first icon at window chat, text information box "Channel" appeared for 1 second, this text box is moving to the left and then disappear. This mechanism was combining text and icon, but with another method. User needs to press the button first, and after that user will read the text information box and understand that button's function. Combined icon with text commonly appeared permanent in the same time, for instance; graphic user interface at footer part of several famous social mobile applications such as Line, BlackBerry (BBM) and WhatsApp.

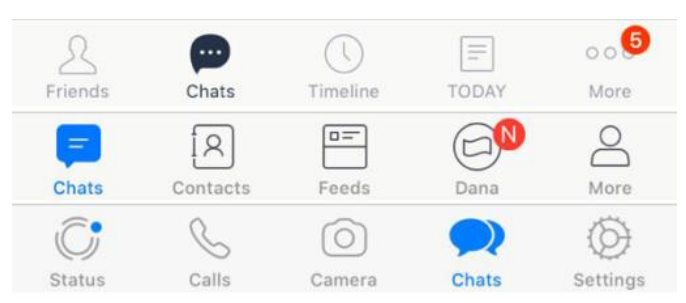

Fig. 6. Footer icon user interface (Blackberry, Line, WhatsApp)

The combination concept for icon and text in the same time will help user to understand the function of every button in the screen, an icon and text will support each other in the interface design. Nevertheless, Ragnarok M: Eternal Love user interface mechanism forced their user to press an icon button whenever the user wants to see an information text. Because of this issue, our research study wants to find correlation between user learning experience towards the user interface mechanism with game sample Ragnarok M: Eternal Love.

\section{RESEARCH METHOD}

This research presented specifically examines the user learning experience in order to understand user interface.

\section{A. Respondent Criteria}

We are considering another learning issue will distract our result if non gamer included in our sample participants. Thus, all our participants must understand about game mobile mechanism, especially MMORPG (Massively Multiplayer Online Role-Playing Game) genre, and all of our participants never try our game sample Ragnarok M: Eternal Love.There were 25 gamers around West Jakarta (Indonesia), our participants are 18 men (72\%) and 7 women (28\%). Their ages ranged from 18-42 years old. 


\section{B. Sampling Technique}

We separated into 2 period of experiment with 1 -week gap between first and the second period. By the beginning of experiment, we asked our participants to play game sample for 1 hour, our participant also got in game mechanism lessons by doing some quest at first field, after that we asked them to answer our questionnaire.

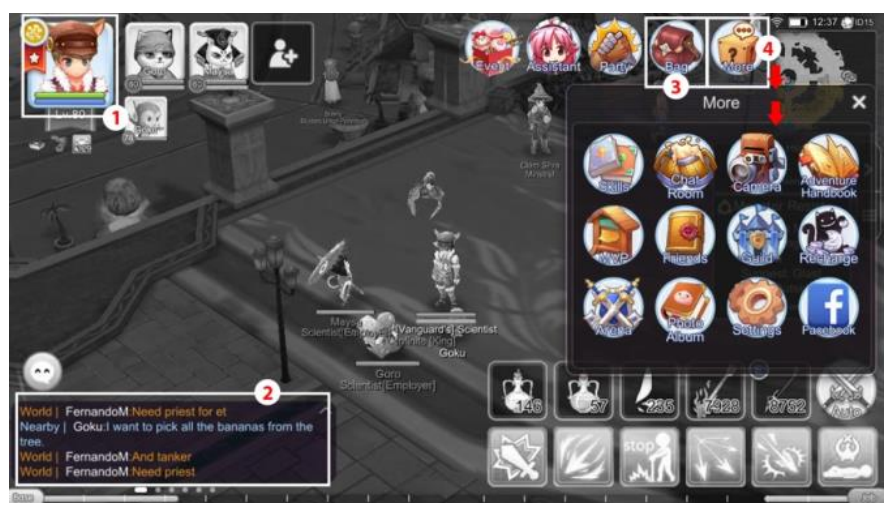

Fig. 7. Ragnarok M: Eternal Love - design interface SEA version

According to Fig 7, displaying a complete interface from the game Ragnarok M: Eternal Love, but in the beginning after created a new character, some features like guild, adventurer handbook and arena were not available in the dropdown "More" menu. Thus, we decided not to give a question about this to our participants. The most important thing to notice in understanding the interface of this game sample is some crucial menu were located separately from one another, so it needs time to familiarize oneself with the layout. Shown by the picture above on Fig 7. Box number 1 is a photo profile of character, this section can be clicked to see the information about this character, it can be a detail or complete data about the character profile such as job and status of character (strength, agility, dexterity, intelligence, luck and vitality). Box number 2 is a section with hover button, user must press it in order to reveal the complete feature of chat box, this game consists of several chat types, there are system chat, world chat, nearby, guild, group, and private chat. In the box number 3 on Fig.7 is a button for open the inventory items, usually consist of a couple of materials, potions, and other equipment that can help increase the ability of the character. In the box number 4, with "More" menu option, this particular button will open a new window that showcase even more buttons (this type of buttons will not show its feature unless it was activated by hovering over it). This "More" menu hold information detail skills of character, chat room, camera, MVP board, friends list, recharge for item mall, photo album, Facebook social media and game settings. For the buttons that comprised inside "More" menu, the game developer of Ragnarok M: Eternal Love used a combination of icon and text to help their users have a better understanding of its function. Nevertheless, when the user needs to understand the details of every feature, game developer changes text from Chinese language (example from Fig 1) into an icon (example from Fig 5 ) with text box in English or Indonesia language will appear for 1 second whenever the user pressed one of the sub-tab button.
We provide 4 questions in order to measurement of understanding game mechanism:

(1) How to chat in the channel?

(2) How to check character equipment?

(3) How to check status of character?

(4) How to change game language?

All of our participants must find the answer by playing the game model, and we will count how long our participants can answer all of our questions.
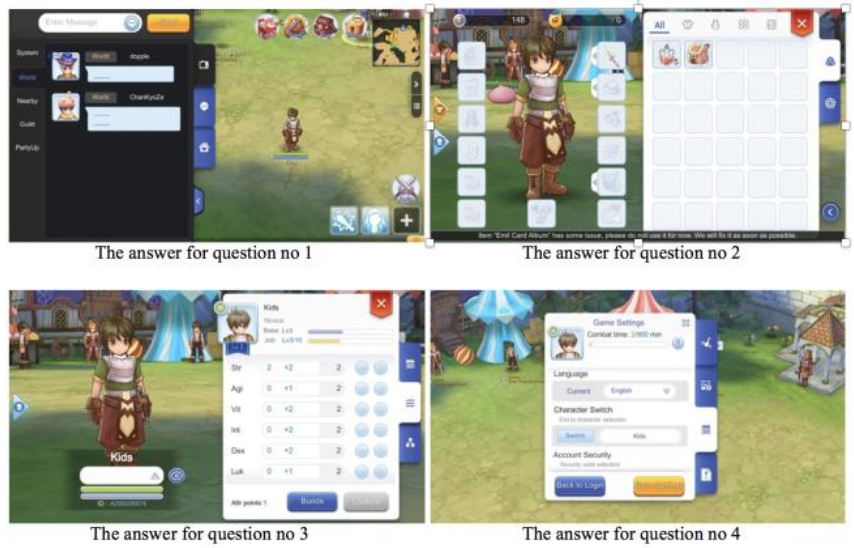

Fig. 8. Answer from first periode experiment.

After this first procedure, we asked to all our participants to continue and play this game. Thus, 1 week later we continued to the second experiment. The basic procedure is same with the first one, our participants must try that game sample at least 1 hour, and answer our questions. We changed the previous 4 questions from first experiment in order to make sure our participants understood about this game user interface, but all these questions have same difficulty with the previous one.

(1) How to whisper chat?

(2) How to check character information?

(3) How to adjust sound system?

(4) How to check job tree of character?
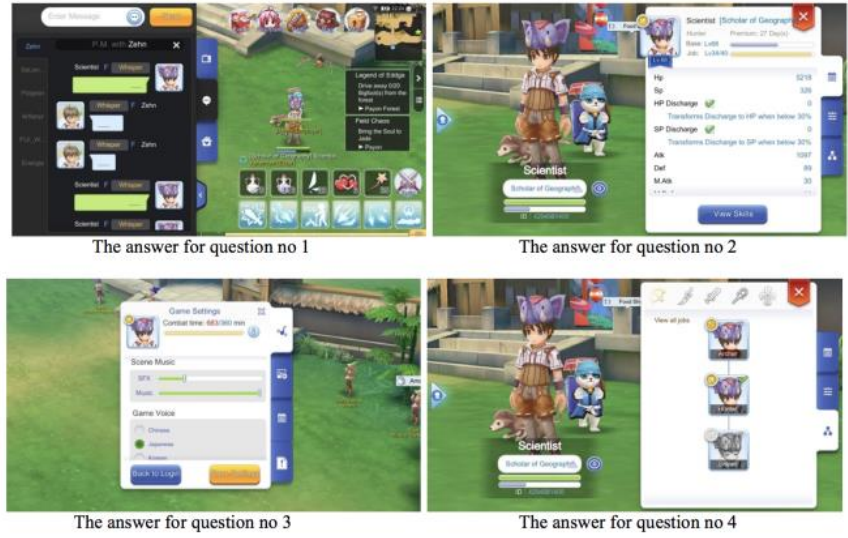

Fig. 9. Answer from second periode experiment. 


\section{Data Processing and Analysis}

We used quantitative method to count learning time from every participant. After we received all of data from 25 participants, we used mean formula for processing it, and we compared the result between first and second experiment.

$$
\begin{gathered}
\overline{\mathrm{x}}=\left(\sum \mathrm{xi}\right) / \mathrm{n} \\
\text { or } \\
\overline{\mathrm{x}}=(\mathrm{x} 1+\mathrm{x} 2+\ldots+\mathrm{xn}) / \mathrm{n}
\end{gathered}
$$

$\overline{\mathrm{x}}$ : sample mean

$\mathrm{x}:$ all questions answered time

$\Sigma \mathrm{x}$ : sum of $\mathrm{x}$

$\mathrm{n}$ : number of participants

Mean is the arithmetic average of the scores. It is computed by adding all the scores and dividing by the total number of scores.

\section{RESULT AND DISCUSSION}

Here it is the data table from 25 participants after tried our game sample Ragnarok M: Eternal Love and answered 4

\begin{tabular}{|c|c|c|}
\hline Participants & 1st Experiment & 2nd Experiment \\
\hline 1 & $231 s$ & $51 \mathrm{~s}$ \\
\hline 2 & $405 \mathrm{~s}$ & $28 \mathrm{~s}$ \\
\hline 3 & $335 \mathrm{~s}$ & $12 \mathrm{~s}$ \\
\hline 4 & $721 \mathrm{~s}$ & $34 \mathrm{~s}$ \\
\hline 5 & $321 \mathrm{~s}$ & $28 \mathrm{~s}$ \\
\hline 6 & $125 \mathrm{~s}$ & $28 \mathrm{~s}$ \\
\hline 7 & $432 \mathrm{~s}$ & $24 \mathrm{~s}$ \\
\hline 8 & $344 s$ & $27 \mathrm{~s}$ \\
\hline 9 & $653 \mathrm{~s}$ & $21 \mathrm{~s}$ \\
\hline 10 & $1021 \mathrm{~s}$ & $31 \mathrm{~s}$ \\
\hline 11 & $235 s$ & $24 \mathrm{~s}$ \\
\hline 12 & $128 \mathrm{~s}$ & $21 \mathrm{~s}$ \\
\hline 13 & $82 \mathrm{~s}$ & $22 \mathrm{~s}$ \\
\hline 14 & $78 \mathrm{~s}$ & $27 \mathrm{~s}$ \\
\hline 15 & $122 \mathrm{~s}$ & $31 \mathrm{~s}$ \\
\hline 16 & $80 \mathrm{~s}$ & $24 \mathrm{~s}$ \\
\hline 17 & $221 s$ & $27 \mathrm{~s}$ \\
\hline 18 & $223 s$ & $31 \mathrm{~s}$ \\
\hline 19 & $421 \mathrm{~s}$ & $30 \mathrm{~s}$ \\
\hline 20 & $310 \mathrm{~s}$ & $29 \mathrm{~s}$ \\
\hline 21 & $642 \mathrm{~s}$ & $25 \mathrm{~s}$ \\
\hline 22 & $208 s$ & $42 \mathrm{~s}$ \\
\hline 23 & $521 \mathrm{~s}$ & $31 \mathrm{~s}$ \\
\hline 24 & $118 \mathrm{~s}$ & $28 \mathrm{~s}$ \\
\hline 25 & $124 \mathrm{~s}$ & $23 \mathrm{~s}$ \\
\hline Mean & $324.04 \mathrm{~s}$ & $27.84 \mathrm{~s}$ \\
\hline
\end{tabular}
questions about user interface and experience.

TABLE I. ALL QUESTION ANSWERED TIME

According to Table 1. The mean score for the first experiment is 324.04 seconds (5.4 minutes), it means our participants need 1.35 minutes in order to answer every question about user interface Ragnarok M: Eternal Love. Nevertheless, after 1 week they have played this game sample and we asked our participants to answer another questionnaire, mean score for the second experiment is 27.84 seconds, it means our participants only need 6,96 seconds to answer every single question. In the first experiment, our participants were confused by the UI (user interface) of Ragnarok M: Eternal Love, they found it difficult and confusing to navigate and find the features that they needed, due to the various style and scattered feature within the game layout. For instance, detail of window chat, character status, items tab, equipment tab, even the game system settings are not appeared in one section. An important issue we got, most participants were having difficulties to find the window chat, this was because of that window chat does not have specific button to open the submenu, most of our participants does not think that box at the screen is for showing a chat full feature. Another issued that we notice is that how the user needs to click every icon button in order to see the text information box appear.

The users with "gamer" profile still need around 4 to 5 minutes average to understand this interface. If it took that much time to navigate the game for a gamer, then we can assume it will take even longer for common people. By the time we conducted this experiment the mobile game Ragnarok M: Eternal Love, had been well known by the Indonesian market. Hence it was easy for us to find participants that willing to play the game for a whole week straight. The result is astonishing, in just a week the participants have memorize and familiarized them self with the navigation system and layout of the game interface, they did not find any significant difficulties answering the questionnaire that we give. This was proven by the average time took by the participants in 6.96 seconds to answer each given question. The results from these two experiments proof that there's a huge gap between the second and the first experiment, where the participants took the average time to answer were up to 1,35 minutes for each question.

\section{CONCLUSION}

The display of the UI (user interface) used by the developer team of Ragnarok M: Eternal Love, had demonstrated a good solution in developing a user interface for mobile game, when confronted by fixed layout and forced to adapt to various different language, but it still need some adjustment time to fully understand the function of every button. The formation of vertical oriented and horizontal oriented button will always face some kind of problem in the application, because the Chinese and Japanese alphabet can easily be implemented in a vertical or horizontal formation, on the contrary that same flexibility does not apply with English and Indonesian language, where the best formation for them are in horizontal formation. Based on our quantitative data, all players can memorize every single button function if they have understood the game system, a good user interface will help them in order to achieve this term.

\section{ACKNOWLEDGMENT}

Thanks to Ragnarok Mobile: Eternal Love team Developer. Gravity Interactive.

\section{REFERENCES}

[1] M. B. Wiryawan, "User Experience (UX) sebagai bagian dari pemikiran desain dalam pendidikan tinggi desain komunikasi visual," Humaniora, vol. 2, no. 2, pp. 1158-1166, 2011.

[2] J. Smith and S. . Esq., "eSports Betting The Past and Future," SCCG 
Manag., no. September, pp. 1-40, 2017.

[3] W. Feng, D. Brandt, and E. V. E. Online, "A Long-Term Study of a Popular MMORPG," NetGames 2007, vol. 1, no. March 2004, pp. $19-24,2007$.

[4] "Ragnarok RO - Heart Network," 2018. [Online]. Available: https://ro.xd.com/. [Accessed: 08-Nov-2018].

[5] A. Zpalanzani and H. Ahmad, "Ragnarok Online, Reality of Virtual Phenomenon," Fsrd.Itb.Ac.Id, 2009.

[6] T. Debeauvais and B. Nardi, "A qualitative study of Ragnarök Online private servers: In-game sociological issues," Environment, pp. 48-55, 2010.

[7] "ROM Producer Interview (English) - YouTube," 2018. [Online]. Available: https://www.youtube.com/watch?v=Q6WXPMUv-Io. [Accessed: 08-Nov-2018].
[8] K. Svartberg, I. Tapper, H. Temrin, T. Radesater, and S. Thorman, "Robust Vertical Text Layout," Anim. Behav., vol. 69, no. 2, pp. 283-291, 2005.

[9] D. Yu, "Comparing reading speed for horizontal and vertical English text," J. Vis., vol. 10, no. 2, pp. 1-17, 2010

[10] M. D. Byrne, "Reading Vertical Text: Rotated vs. marquee," Proc. Hum. Factors Ergon. Soc. Annu. Meet., vol. 46, no. 17, pp. 1633$1635,2002$.

[11] R. Yan, "Icon design study in computer interface," Procedia Eng., vol. 15, pp. 3134-3138, 2011.

[12] Y. Y. Choong and G. Salvendy, "Design of icons for use by Chinese in mainland China," Interact. Comput., vol. 9, no. 4, pp. 417-430, 1998. 